\title{
Fly ash and zinc slag blended geopolymer: Immobilization of hazardous materials and development of paving blocks
}

\author{
S.K. Nath \\ CSIR- National Metallurgical Laboratory, Jamshedpur 831 007, India
}

\section{A R T I C L E I N F O}

\section{Editor: Deyi Hou}

Keywords:

Fly ash

Zinc slag

Geopolymer

Reactivity

Leach-ability

Paving block

\begin{abstract}
A B S T R A C T
The potential for practical application of fly ash, zinc slag and their blends for geopolymer synthesis at ambient temperature have been investigated in this paper. Fly ash is an alumino-silicate byproduct suitable for geopolymer reaction, but its low reactivity at ambient condition is the restriction of its bulk utilization. Above limitation can be overcome by blending with zinc slag (ZS). Additionally, ZS contains heavy and toxic metals ( $\mathrm{Pb}$, $\mathrm{Zn}, \mathrm{Cr}, \mathrm{Cd}, \mathrm{As}$ ), which can be stabilize in $\mathrm{Al}-\mathrm{Si}$ based geopolymer network structure. Isothermal conduction calorimetry (ICC) is used to monitor the geopolymer reaction with time. Slag rich specimens are characterized with higher rate of reaction with augmented peak. The mineralogy and microstructure of the geopolymers have been examined through X-ray diffraction and scanning electron microscope. The detected chief reaction product is $\mathrm{N}-(\mathrm{C})-\mathrm{A}-\mathrm{S}-\mathrm{H}$ and $\mathrm{C}-(\mathrm{N})-\mathrm{A}-\mathrm{S}-\mathrm{H}^{1}$ type hydrated gel. Continual improvement of compressive strength of the geopolymers with increasing slag content is explained with higher degree of reaction, formation of more reaction products and development of compact microstructure. According to toxicity characteristic leaching procedure (TCLP), toxic metals leaching is within permissible limit. Paver blocks using $40-80 \mathrm{wt} \% \mathrm{ZS}$ has been developed, which meets IS 15,658: 2006 standard and comply with US-EPA specification.
\end{abstract}

\section{Introduction}

In recent time, geopolymer has become one of the attractive materials for the replacement of ordinary Portland cement (OPC). It has been considered as green alternative of Portland cement due to its lower carbon footprint and lesser embodied energy requirement during production (Yang et al., 2013; Gartner and Hirao, 2015). Additionally, it exhibits superior properties such as good mechanical strength, excellent chemical and fire resistant properties than OPC binder, and its tailor made properties make suitable for wide range of applications (Fernández-Jiménez et al., 2006; Park et al., 2016; Hassan et al., 2019; Luhar et al., 2019). It is defined as a class of binder material containing -Si-O-Al- bond in a tri-dimensional network structure, formed by the interaction of alkaline solution with a powder source containing $\mathrm{Al}_{2} \mathrm{O}_{3}$ and $\mathrm{SiO}_{2}$ such as calcined clay, fly ash, blast furnace slag, silico-manganese slag, Pb-Zn slag, red mud, mining waste etc. (Davidovits, 1989; Ma et al., 2012; Onisei et al., 2012; Kumar and Kumar, 2013; Yun-Ming et al., 2016; Kiventera et al., 2018; Millán-Corrales et al., 2018; Nath and Kumar, 2019a; Xia et al., 2019).

The proper disposal and effective utilization of hazardous waste has become a major challenge to the industry, due to stringent environment protection rules and regulations by the administration. Geopolymer technology provides a sustainable solution towards waste utilization, pollution mitigation and resource conservation by using waste materials as precursor (Fernández-Jiménez and Palomo, 2003; Onisei et al., 2012; Lee et al., 2016; Kumar et al., 2017; Koplík et al., 2018; Nie et al., 2019; Xia et al., 2019). As a result, a huge number of industrial byproducts and wastes have been examined for solidification/stabilization through geopolymer technology (Xu et al., 2014; Nazari and Sanjayan, 2015; Djobo et al., 2016; Lirer et al., 2017; Kiventera et al., 2018; Koplík et al., 2018; Nath, 2018; Hassan et al., 2019; Luhar et al., 2019; Nie et al., 2019).

In this manuscript, two industrial wastes, namely fly ash (FA) and zinc slag (ZS) have been explored for geopolymer paving block production at ambient condition. FA is a by-product of coal fired thermal power plant, reported as suitable precursor for geopolymer synthesis in numerous articles because of its Al-Si composition, glassy nature, spherical form, low water requirement and high workability (Temuujin et al., 2009; Rodríguez et al., 2013; Lee et al., 2016; Nath and Kumar, 2019b). Although, its slow reaction with alkali, slow hardening and subsequent low strength development at ambient condition restrict its utilization in geopolymer. To overcome the low reactivity of FA, it is often blended with other reactive waste which contains higher amount of CaO (Lee and Lee, 2013; Nath and Sarker, 2014; Park et al., 2016;

E-mail address: snath@nmlindia.org.

${ }^{1}$ (where, $\mathrm{N}=\mathrm{Na}_{2} \mathrm{O}, \mathrm{C}=\mathrm{CaO}, \mathrm{A}=\mathrm{Al}_{2} \mathrm{O}_{3}, \mathrm{~S}=\mathrm{SiO}_{2}$ and $\mathrm{H}=\mathrm{H}_{2} \mathrm{O}$ ) 
Nath, 2018). Due to adequate $\mathrm{CaO}$, cementiceous C-S-H/C-A-S-H gel is formed in addition with N-A-S-H geopolymer gel, which improves binding capability and results early strength development (Gao et al., 2015; Djobo et al., 2016; Park et al., 2016; Nath and Kumar, 2019a). In this paper, ZS is gradually introduced into FA based control sample and the effect of slag introduction is studied, which is yet to be unveiled.

$\mathrm{ZS}$ is a byproduct produced from imperial smelting furnace (ISF) method, contains $\mathrm{SiO}_{2}, \mathrm{Al}_{2} \mathrm{O}_{3}, \mathrm{CaO}$ and $\mathrm{Fe}_{2} \mathrm{O}_{3}$ as major oxide components. The ratio of silica to alumina $(\mathrm{Si} / \mathrm{Al} \sim 3)$ is not appropriate to build a rigid Al-Si network structure after geopolymerization. ZS also contains heavy and toxic elements such as $\mathrm{Pb}, \mathrm{Zn}, \mathrm{Cd}, \mathrm{Cr}, \mathrm{Ag}, \mathrm{As}, \mathrm{Ba}, \mathrm{Cu}$ etc. (Alex et al., 2013; Hu et al., 2014; Xia et al., 2019), which limits its utilization as building materials for chances of leaching. Geopolymer has the potential to immobilize heavy and toxic metal but deficiency in $\mathrm{AlO}^{4-}$ unit can reduce its efficiency. However, the exact immobilization mechanism either by chemical bonding and physical encapsulation is yet to be clear (van Jaarsveld and van Deventer, 1999; Izquierdo et al., 2009; Ogundiran et al., 2013; Lee et al., 2016; Koplík et al., 2018), but several authors demonstrated that heavy metals may possibly bond with alumina tetrahedron (van Jaarsveld and van Deventer, 1999; Zhang et al., 2007; Lee et al., 2016; Fernández-Pereira et al., 2018). Therefore, FA compensates the $\mathrm{Al}$ deficiency in the mixture and improves the immobilization efficiency of the heavy metals in ZS. As far author's knowledge, this approach is not yet reported in anywhere. Another justification of above blending for geopolymer production is the generation ratio of FA and ZS. Around 1 million ton per annum ZS in produced worldwide, and in India the annual production is about 50,000 ton (Alex et al., 2013). Fly ash is produced in much higher volume ( $\sim 230$ million ton in India only) and easily available. Therefore, by blending the total volume of the resource material for geopolymer synthesis is augmented. In normal practice by industry, ZS is thrown away and simply dumping which is no more a sustainable process and causes severe environmental degradation and lack of aesthetics.

The aim of this work is synergistic utilization of ZS and FA through ambient temperature geopolymerization. Another objective is to overcome the limitation of stabilization/solidification of FA and ZS into geopolymer by blending them, and to develop environmental friendly paving blocks with desired properties.

\section{Materials and methods}

Class F fly ash used for this study was received from Tata Power Co. Ltd., Jamshedpur, India. Zinc slag in granular form $(0.2-3 \mathrm{~mm}$ size), was collected from Hindusthan Zinc Ltd., Chanderiya, Rajasthan, India. The slag was ball milled for $2 \mathrm{~h}$ to obtain powder of median particle size, $D_{50} \leq 25 \mu \mathrm{m}$. The chemical analysis of fly ash and slag was carried out by using Inductive coupled plasma optical emission spectrometer (ICP-OES) (Make: Varian Inc.) and further verified in X-ray florescence (XRF, Make: Bruker, US). Loss on ignition (LOI) was estimated by measuring the weight loss upon heating at $950{ }^{\circ} \mathrm{C}$ and $30 \mathrm{~min}$ holding, repeated for three times and average value was taken. Specific gravity of fly ash and slag powder samples were measured by using Pycnometer bottle by following Archimedes principles. Laser particle size analyzer (Make: Malvern, UK) was used for the determination of particle size distribution (PSD) of fly ash and milled slag. Table 1 shows the oxide content and physical characteristics of the raw materials. The mineralogy of raw materials were analysed by using D8 Discover X-ray powder diffractometer (XRD, Make: Bruker, US) in the range of 10 to $70^{\circ} 2 \theta$ with $0.2 \mathrm{~s} /$ step scan speed and step size of $0.02^{\circ}$. The $C u K_{\alpha}$ radiation $(=1.5418 \AA$ ) was generated at $40 \mathrm{kV}$ and $40 \mathrm{~mA}$. Approximately $5 \mathrm{~g}$ of powder sample was collected after cone and quartering of bulk sample, then kept on sample holder and levelled with glass plate.

The mix proportion was used for this study is shown in Table 2. Sample nomenclature has two parts, numerical represents percentage used and alphabetic indicates initial of the each component. For isothermal conduction calorimeter (ICC) test, $6 \mathrm{M} \mathrm{NaOH}$ solution was used
Table 1

Chemical analysis and physical properties of raw materials.

\begin{tabular}{lll}
\hline Constituents (Wt.\%) & $\mathrm{FA}^{\mathrm{a}}$ & $\mathrm{ZS}$ \\
\hline Chemical analysis & & \\
$\mathrm{SiO} 2$ & 51.20 & 27.10 \\
$\mathrm{Al2O} 3$ & 28.60 & 7.65 \\
$\mathrm{CaO}$ & 2.15 & 17.95 \\
$\mathrm{MgO}$ & 0.75 & 4.70 \\
$\mathrm{ZnO}$ & 0.01 & 1.30 \\
$\mathrm{PbO}$ & 0.02 & 0.03 \\
$\mathrm{FeO}+\mathrm{Fe} 2 \mathrm{O} 3$ & 8.10 & 35.30 \\
$\mathrm{LOI}$ & 2.70 & 0.60 \\
Physical properties & & \\
Specific gravity & 2.3 & 3.1 \\
Median particle size $(\mu \mathrm{m})$ & 9.67 & 20.54 \\
\hline
\end{tabular}

${ }^{\mathrm{a}}$ Fly ash contains trace amount of $\mathrm{P}_{2} \mathrm{O}_{5}, \mathrm{PbO}, \mathrm{BaO}$ etc.

Table 2

Batch composition used.

\begin{tabular}{lllll}
\hline Name & FA & ZS & Si/Al & $(\mathrm{Ca}+\mathrm{Mg}) / \mathrm{Si}$ \\
\hline 100FA & 100 & 00 & & 0.083 \\
80FA20ZS & 80 & 20 & 1.674 & 0.217 \\
60FA40ZS & 60 & 40 & 1.811 & 0.384 \\
40FA60ZS & 40 & 60 & 2.02 & 0.593 \\
20FA80ZS & 20 & 80 & 2.376 & 0.350 \\
100ZS & 00 & 100 & 3.122 & 1.236 \\
\hline
\end{tabular}

as activator, prepared by dissolving analytical grade sodium hydroxide flakes (purity $\sim 97 \%$, Merck, Germany) into calculated amount of distilled water. $6 \mathrm{M}$ alkali solution was selected based on our previous work on fly ash, slag and blended geopolymers (Nath and Kumar, 2013, 2017; Nath, 2018). With increasing alkali concentration, there could be improvement in strength, but at the same time chances of alkali leaching and efflorescence could be more, handing could be difficult due to more corrosiveness. Furthermore, higher concentration can lead to slow reactivity due to presence of excess $\mathrm{OH}^{-}$in the system. The geopolymer reaction was monitored in an Isothermal conduction calorimeter (ICC, Make: TA instrument) at $\pm 27^{\circ} \mathrm{C}$. For sample preparation, powder and alkaline solution in 2:1 ratio was mixed manually in calorimeter bottle. Then the bottles were sealed at outside and then loaded into calorimeter channels. $2-3 \mathrm{~min}$ time was elapsed between sample mixing and loading into calorimeter channels.

The same X-ray diffraction (XRD) technique as mentioned earlier was used to detect the crystalline phases after geopolymerization. Hardened geopolymer sample was crushed in mortar and pestle into powder of $<45 \mu \mathrm{m}$ sizes, then kept on sample holder and level with glass plate. Microstructural analysis of the geopolymer after silver coating on fractured surface was carried out under Field emission gunscanning electron microscope (FEG-SEM, Make: FEI, Netherlands) operated at $15.0 \mathrm{KV}$ and elemental analysis was done with Energy dispersive X-ray spectroscopy (EDX). EDX was carried out at least six different points on similar feature of all samples to minimize the error due to samples heterogeneity, and reaction non-uniformity.

Cube $(50 \times 50 \times 50 \mathrm{~mm})$ sized samples were prepared for compressive strength test. Composite solution of $6 \mathrm{M} \mathrm{NaOH}$ and sodium silicate (SS) (7.5-8.5 wt.\% $\mathrm{Na}_{2} \mathrm{O}, 25-\mathrm{wt} . \% \mathrm{SiO}_{2}$ and rest amount of water, modulus 3.45 ) in 1:1 vol ratio was used. Generally sodium silicate solution was added for developing sufficient handling strength at the early stage, reported by numerous authors (Criado et al., 2005; Nath, 2018; Nath and Kumar, 2019a). Higher sodium silicate to $\mathrm{NaOH}$ ratio can results better compressive strength (Chindaprasirt et al., 2007), but leads to low workability. Thus, extra water or solution is required to further achieve the desired workability. This increases the water to binder ratio which has a negative effect on strength 
development (Nath and Sarker, 2014). Based on our experience, sodium silicate to $\mathrm{NaOH}$ ratio is optimized at 1 (Nath and Kumar, 2017; Nath, 2018). The main focus of this paper is to study of fly ash and zinc slag blends into geopolymer products, their characterizations and leachability testing. To obtain a homogenous and consistent paste, powder and alkali solution (around $28 \mathrm{wt}$. \%) was mixed in a mechanical mixer, and then, casted in cube shaped steel moulds. The hardened samples were de-moulded after $24 \mathrm{~h}$ of casting and kept in plastic cover at $27 \pm 2{ }^{\circ} \mathrm{C}$ temperature for further curing. After 7, 14 and 28 days of curing, samples were taken out from plastic bag for compression test using ACTM (make: AIMIL, India).

The physical properties of the paving blocks prepared using FA and ZS mix was tested as per Indian standard IS 15658: 2006 specification (IS 15658, 2006). The leach-ability of the geopolymer powder samples was tested using toxicity characteristic leaching procedure protocol as per EPA 1311 (EPA 1311, 1992). $100 \mathrm{~g}$ dry powder of $<100 \mu \mathrm{m}$ particle size was obtained by dry grinding of geopolymeric samples in mortar and pestle, followed by addition with glacial acetic acid in TCLP bottle. The bottles were agitated at $30 \mathrm{rpm}$ in a rotary agitator (Model: Y132 ORA HW, Make: Milipore) for $18 \mathrm{~h}$. The obtained slurry was then filtered and the leach liquor was analyzed using ICP-OES.

\section{Results and discussion}

\subsection{Characterizations of raw materials}

Around $80 \mathrm{wt} . \%$ of total oxide components of FA are comprised of $\mathrm{SiO}_{2}$ and $\mathrm{Al}_{2} \mathrm{O}_{3}$. The rest is minor constituent of iron oxide, $\mathrm{CaO}$ and other impurities. Zinc slag (ZS) contains $\mathrm{SiO}_{2}, \mathrm{Al}_{2} \mathrm{O}_{3}$, iron oxide and $\mathrm{CaO}$ as major and $\mathrm{MgO}, \mathrm{ZnO}$ as minor. Fig. 1 shows the particle size distribution (PSD) of FA and milled ZS. ZS is coarser than FA with higher median particle size, although distribution pattern is similar. XRD profile of both raw materials shows crystalline peaks and glassy bump, Fig. 2(a-b). At $20-30^{\circ} 2 \theta$ range a broad hump is detected which corresponds to glassy or amorphous fraction of fly ash (Fig. 2a). Quartz (JCPDS 85-0796) and mullite (JCPDS 74-4143) are identified as prime crystalline phases of fly ash (Fig. 2a) (Nath, 2018). The broad hump in $2 \theta$ of $25-40^{\circ}$ in ZS (Fig. 2b) indicates its glassy part along with detected crystalline peaks of calcium iron silicate (JCPDS 87-1704) and magnesioferrite (JCPDS 89-4924), mainly the combination of different oxide components.

\subsection{Study of geopolymerization behavior}

The heat of reaction $(\mathrm{dQ} / \mathrm{dt}, \mathrm{mW} / \mathrm{g})$ with time $(\mathrm{h})$, as recorded by

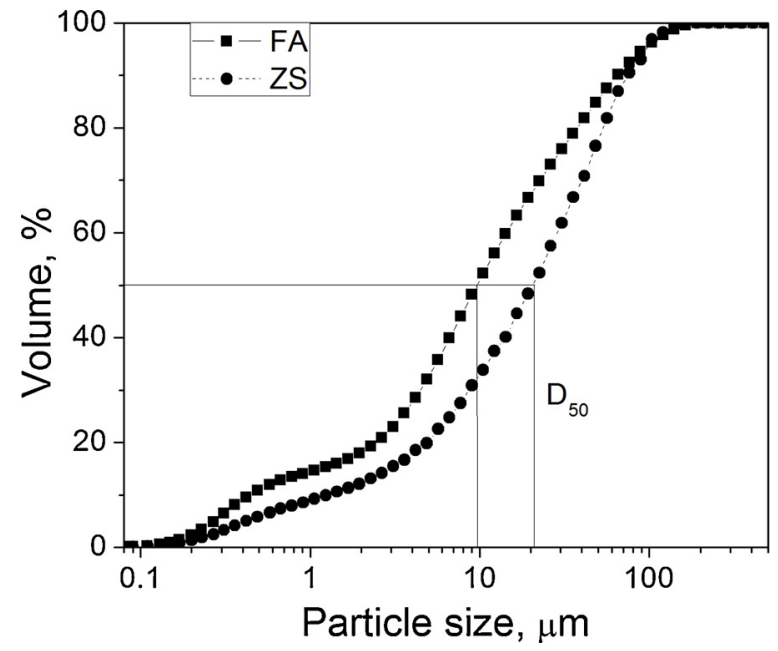

Fig. 1. Particle size distribution of fly ash and ZS.
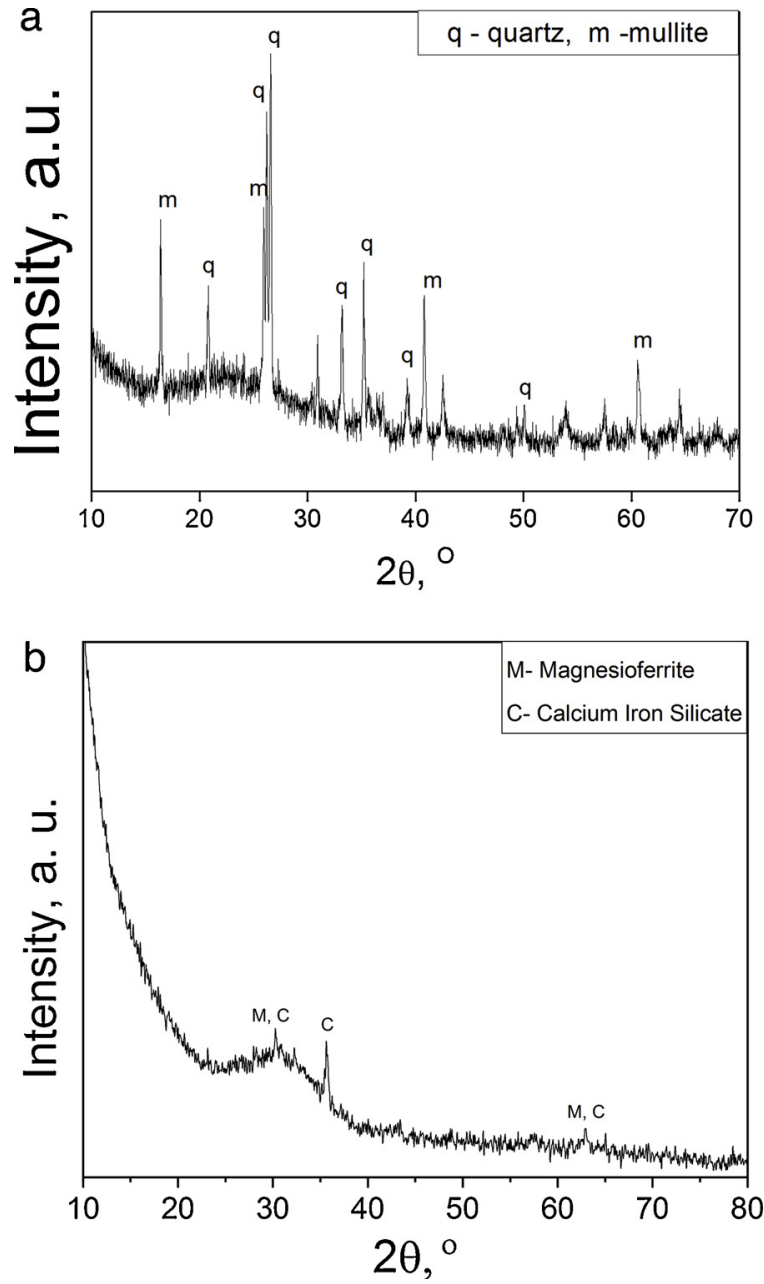

Fig. 2. a): XRD analysis of fly ash (Nath, 2018), b) XRD analysis of ZS

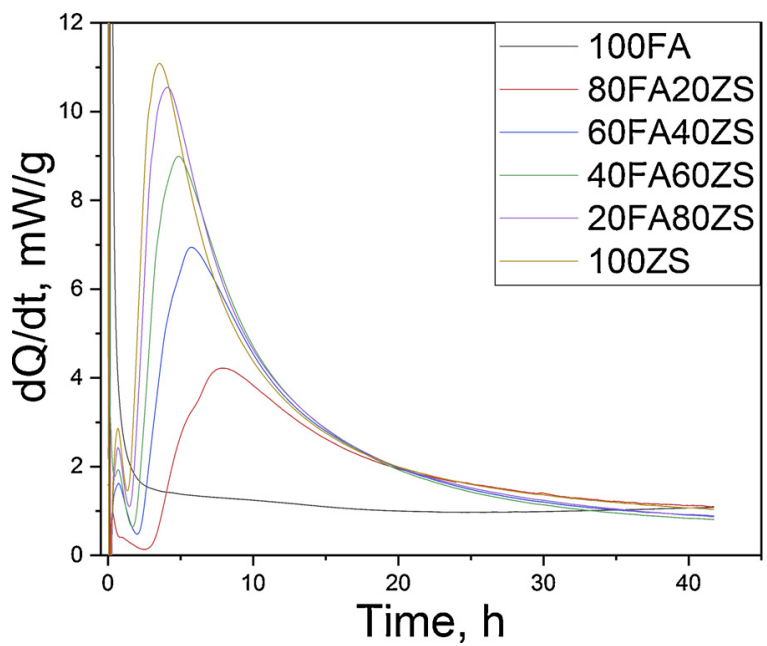

Fig. 3. Isothermal conduction calorimetry showing heat of reaction of fly ash, fly ash-ZS blends and ZS with alkali solution.

ICC is represented in Fig. 3. In all samples just after start of recording, a vertical line or sharp peak (I) is appeared due to wetting and initial dissolution of precursor powder particles into alkali solution (Gao et al., 2015; Nath and Kumar, 2017; Nath, 2018). Thereafter an induction phase with marginal heat release is observed. At studied condition i.e. $\sim 27^{\circ} \mathrm{C}$ temperature and $6 \mathrm{M}$ activator, no further peak is recorded with only fly ash sample (100FA), except one extended horizontal line, 
attributes with its extremely low reactivity, coherent with existing literatures (Temuujin et al., 2009; Kumar et al., 2017; Nath and Kumar, 2019a). The peak nature has been started to alter after blending with slag. As a result, a small peak is recorded after the induction period which is associated to continuous dissolution of ZS and initial precipitation of $\mathrm{Ca}$ bearing reaction products. Thereafter, another induction phase is detected, followed by the main peak with very prominent acceleration and declaration step of reaction. This peak is assigned to massive precipitation and polymerization of the reaction products in large amount. The peak characteristics such as starting point, maxima and sharpness are altered with slag content. These variations can be associated with the degree of dissolution and availability of reactive oxide amount after dissolution. ZS comprises with higher amount of $\mathrm{CaO}$ which is more vulnerable to dissolve than $\mathrm{Al}_{2} \mathrm{O}_{3}$ and $\mathrm{SiO}_{2}$, under the polarization effect of $\mathrm{OH}^{-}$(Nath and Kumar, 2016). Therefore, the Ca containing hydrated products which are primarily formed, consumes more $\mathrm{Ca}$ from solution phases and enhances the slag dissolution rate. This has been resulted a driving force for forwarding the reaction (Nath, 2018). As a result, the slag dissolution occurs at much faster rate and progressive reaction towards precipitation, gelation and reorganization has been initiated earlier. Apart from $\mathrm{Al}_{2} \mathrm{O}_{3}, \mathrm{SiO}_{2}, \mathrm{CaO}$ and $\mathrm{MgO}$, the role of $\mathrm{ZnO}$ is also reported in literature (Garg and White, 2017). These authors have explained the retardation effect of nano-ZnO on alkali activated blast furnace slag. They have observed an extended induction period at the initial stage of reaction by forming calcium zincate (CZ) phase, but his effect is not much effective at later age of reaction. However, in present work, the effect of $\mathrm{ZnO}$ on reactivity is not detected by ICC study. The probable reason can be change of precursor powder nature and availability of reactive components. In the above said work, nano- $\mathrm{ZnO}$ is used separately which might be more reactive than $\mathrm{ZnO}$ available from slag. Another reason can be blast furnace slag contains higher amount of reactive $\mathrm{CaO}$ (almost double than zinc slag) in glassy form which is readily dissolved in alkali and available for reaction with nano-ZnO to form $\mathrm{CZ}$ at the initial reaction time. With ZS incorporation, the peak corresponds to the main reaction is initiated earlier and getting sharper. The peak maxima is augmented and positioned at lower time. This signifies higher reactivity of ZS compare to FA, at the studied condition. The reactivity of slag rich blends is boosted due to increase of reactive oxides with $\mathrm{ZS}$ addition, coherent with several publications (Nath and Kumar, 2013; Park et al., 2016; Nath and Kumar, 2019a). Finally, a low reactive zone with very minimal heat release is recorded and called as decay state or finishing of reaction. At this stage, the polymerization and condensation reactions are possibly continuing for a longer period with lower amount of heat release. ZS rich samples are approaching decay state earlier because of faster reaction rate.

The integrated heat $(Q)$ of reaction (Fig. 4) has been increased with ZS introduction due to higher reactivity of ZS. The flatter region at the initial stage is related to dormant period of the reaction which is reduced with ZS inclusion. Then the heat release curve is continuously increased with the progress of reaction. The peak flatness is more with FA rich samples, attributes very low reactivity and lower heat of reaction with FA dominated system.

\section{3. $X$-ray diffraction $(X R D)$ analysis}

Fig. 5(a-b) depict the X-ray diffraction pattern of geopolymer samples. XRD profile shows mostly two distinct characteristics, crystalline peaks and amorphous hump. Structural reorganization of the raw materials after geopolymerization is supported by the change in peak and hump characteristics. Quartz and mullite are the main identified crystalline phases of fly ash rich geopolymer samples which come from remnant part of fly ash (Fig. 5a). Fly ash is mostly un-reactive at experimented conditions $\left(\sim 27^{\circ} \mathrm{C}\right.$ temperature with $6 \mathrm{M}$ alkali) and therefore, crystalline phases are retained even after 28 days curing. The crystalline phases of FA, quartz and mullite are traced as major, even 60 $\%$ FA is replaced with ZS. The X-ray diffractogram of $\geq 80 \mathrm{wt} \%$ slag

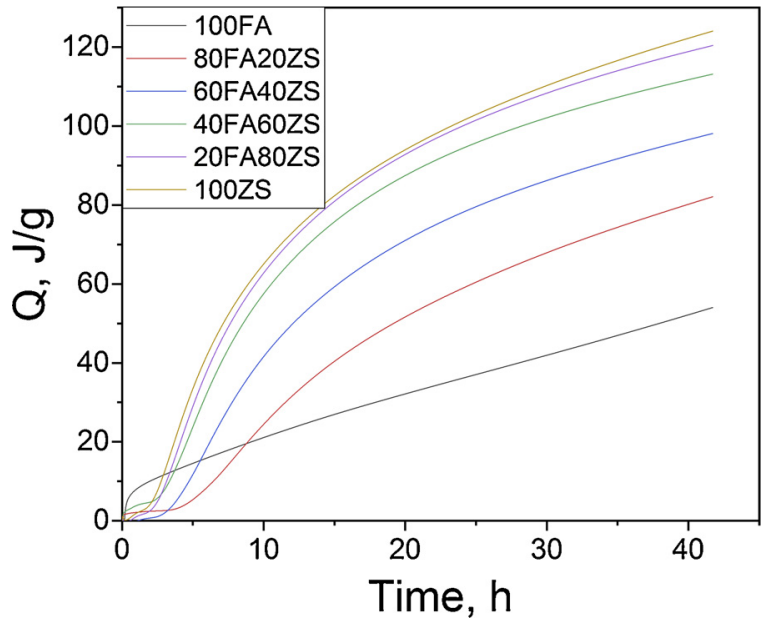

Fig. 4. Integrated heat of reaction of fly ash, fly ash-ZS blends and ZS with alkali solution.
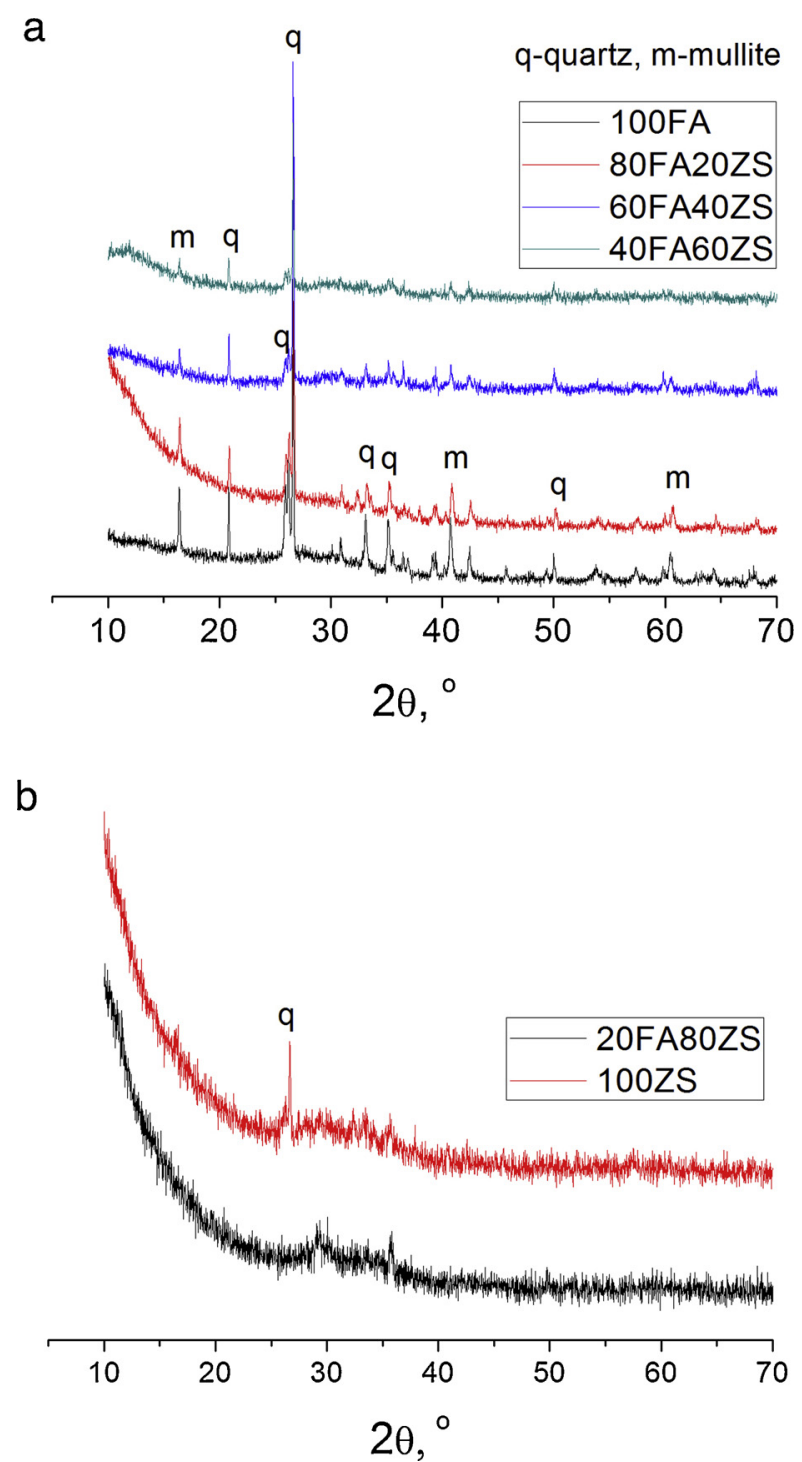

Fig. 5. a): XRD analysis of geopolymer cement paste samples. b): XRD analysis of geopolymer cement paste samples. 
containing samples are entirely different and no sharp crystalline peaks are detected. One extra quartz peak at $\sim 27^{\circ} 2 \theta$ is identified with 100ZS sample. The probable reason can be transformation of quartz from intermediate $\mathrm{SiO}_{2}-\mathrm{X} / \mathrm{Y}$ phases, which are precipitated from alkali solution $(\mathrm{NaOH})$ containing dissolved $\mathrm{SiO}_{2}$ even at low temperature (Wijnen et al., 1989; Kumar et al., 2017).

The poorly crystalline gel phases of separate composition such as $\mathrm{N}$ A-S-H, N-(C)-A-S-H, C-A-S-H, C-(N)-A-S-H and C-(M)-A-S-H are formed as reaction product in the FA, FA-ZS blends and ZS derived geopolymers. These phases are not traced by XRD, although formation of the zeolite phases is reported in several occasions (Ma et al., 2012; Rodríguez et al., 2013). The above gels are produced by alkali activation of both Al-Si rich FA and Ca rich slag, and co-exist in the reacted matrices without having any distinct boundary (Yip et al., 2005; Nath and Kumar, 2019a). Detection of those non-standard minerals are difficult through XRD pattern due to their amorphous to semi-crystalline nature and overlapping with other remnant peaks, in consistent with previous researches (Criado et al., 2005; Xu et al., 2014). The characteristics change of glassy hump of both precursor materials after alkali activation is attributed with structural reorganization of the reacted amorphous fraction due to inclusion of $\mathrm{Na}$ and/or $\mathrm{Ca}$, and modification of the hydration state of the Si-Al network (Kumar et al., 2017). For further understanding, SEM-EDX of those specimens are carried out and discussed in next Section 3.5. Tobermorite, $\mathrm{Ca}_{5} \mathrm{Si}_{6} \mathrm{O}_{16}(\mathrm{OH})_{2}$ (JCPDS 191364), a secondary product is formed from C-A-S-H gel, detected with very low intensity and probably overlapping with iron bearing phases, coherent with earlier reports on alkali activated sole slag system (Alex et al., 2013; Zhang et al., 2016).
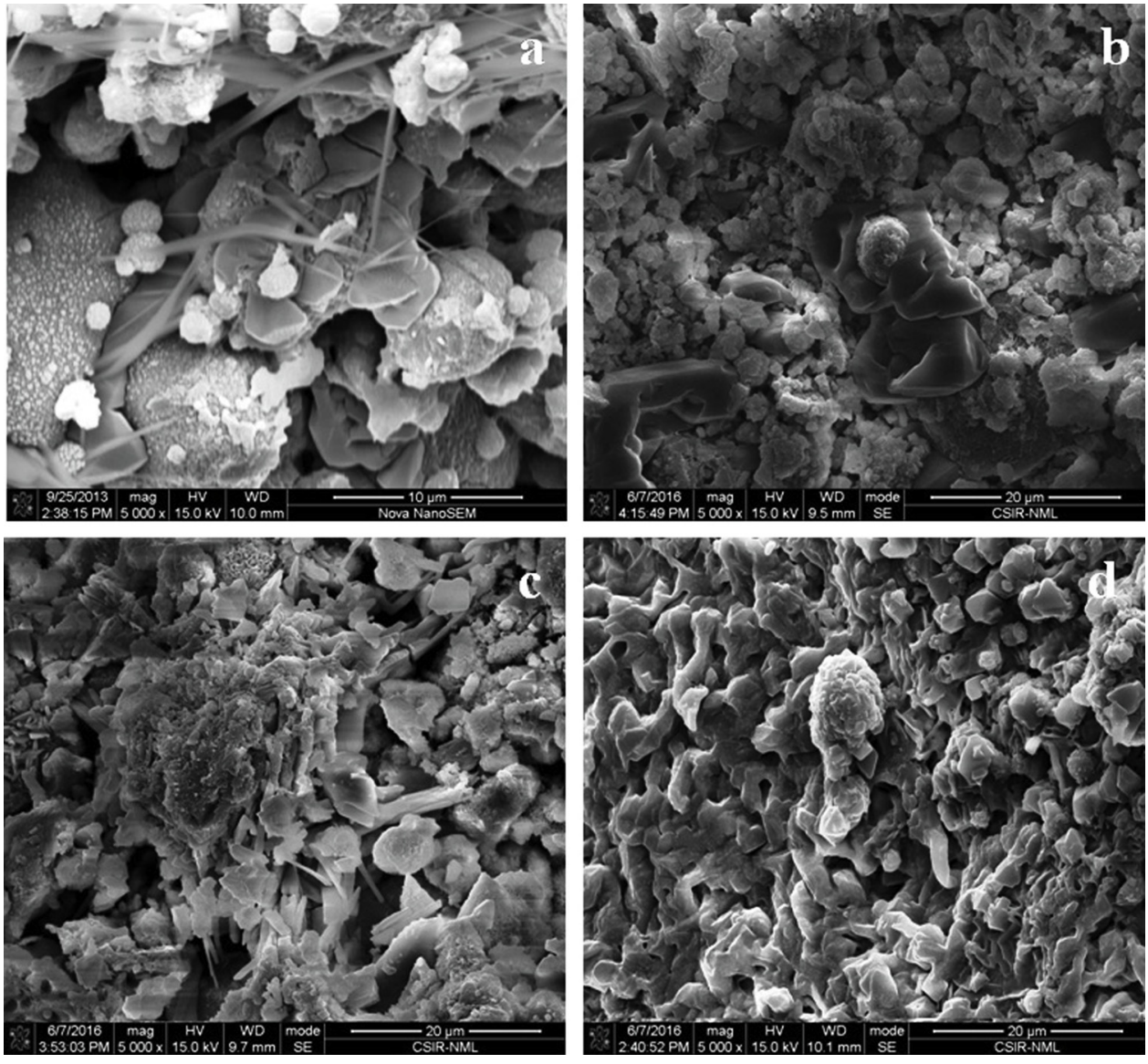

Fig. 6. SEM image of fractured surface of geopolymer cement paste samples; (a) 100FA, (b) 60FA40ZS, (c) 20FA80ZS and (d) 100ZS.

\subsection{Morphological analysis}

The micrographs of the geopolymers fractured surface are shown in Fig. 6(a-d). A non-homogeneous composite comprising of gel, un-reacted, partially and/or fully reacted particles are the common features of all microstructures. The gels are generally produced from fully/ partially reacted FA and/or ZS particles. Gel formation is observed in scattered manner on the surface of particles. Compare to coarser, finer particles are more diffused because of faster dissolution and subsequent precipitation. The typical characteristics of geopolymer micrographs and elemental analysis using EDX are shown in Table 3. EDX analysis is presented by considering four major elements; $\mathrm{Si}, \mathrm{Al}, \mathrm{Na}$ and $\mathrm{Ca}$ as 100 $\%$ in total. A wide variation is observed in the chemical composition of the reacted gel, attributes with different properties such as oxide composition, reactive glass percentage and granulometry (particle size and shape) of FA and ZS. Finally, this leads to different reactivity and formation of reaction product of individual nature. However, these reacted gels are intermixed so intimately in the blended matrix (Fig. 6b and c), that their separate identification on micro and macro structural levels is difficult task. The particles in FA derived geopolymer (100FA) matrix are partly diffused and are mostly retained their spherical shapes (Fig. 6a). This specimen is also characterized by lower fraction of gel (uniform nature, point A) formation and development of fibrous like $\mathrm{Na}$ rich features. These fibrous features are secondary product and produced as per following reaction (1)-

$\mathrm{SiO}_{2}$ (soluble) $+2 \mathrm{NaOH}($ soln $) \rightarrow \mathrm{Na}_{2} \mathrm{OSiO}_{2}+\mathrm{H}_{2} \mathrm{O}$

With moderate alkali concentration and at ambient temperature ( $\pm 27^{\circ} \mathrm{C}$ ), sodium silicate formation is favorable due to availability of soluble silica from fly ash, agrees with existing literature on fly ash geopolymer (Nath et al., 2016). FA rich specimens (100FA and

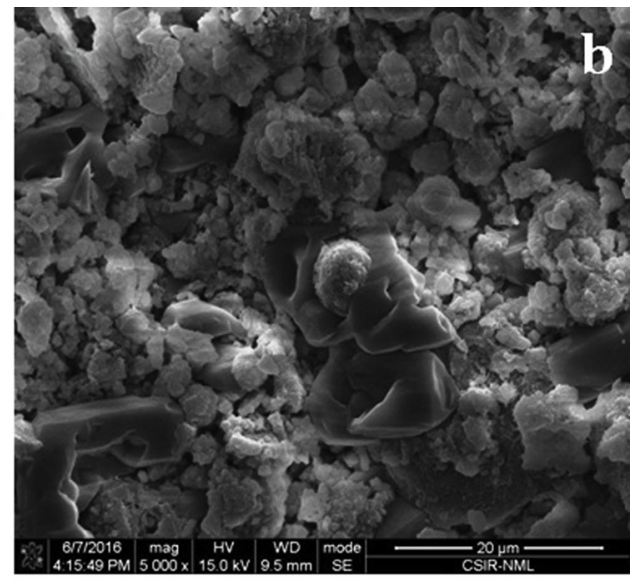


Table 3

The average elemental analysis by EDX analysis of reacted geopolymer matrix (\%).

\begin{tabular}{|c|c|c|c|c|c|c|}
\hline Sample & SEM Fig. & Typical features & $\mathrm{Si}$ & $\mathrm{Al}$ & $\mathrm{Na}$ & $\mathrm{Ca}$ \\
\hline \multirow[t]{2}{*}{ 100FA } & \multirow[t]{2}{*}{ Fig. $6 \mathrm{a}$} & Scattered gel by partly diffused particles (point A) & 49.73 & 28.82 & 19.26 & 2.19 \\
\hline & & Na rich fibrous form (point $B$ ) & 33.62 & 11.13 & 53.91 & 1.34 \\
\hline \multirow[t]{2}{*}{ 60FA40ZS } & \multirow[t]{2}{*}{ Fig. 6b } & Porous gel in discrete manner (point A) & 43.45 & 24.78 & 17.09 & 14.68 \\
\hline & & Dense Ca rich particles (point B) & 38.16 & 9.47 & 4.25 & 48.12 \\
\hline \multirow[t]{2}{*}{ 20FA80ZS } & \multirow[t]{2}{*}{ Fig. $6 \mathrm{c}$} & Dense gel with irregular shape (point A) & 39.83 & 16.19 & 14.41 & 29.57 \\
\hline & & Gel formation on upper surface in scattered manner (point B) & 44.69 & 21.15 & 15.53 & 18.63 \\
\hline \multirow[t]{2}{*}{$100 \mathrm{ZS}$} & \multirow[t]{2}{*}{ Fig. 6d } & Dense gel with uniform matrix (point A) & 34.53 & 11.18 & 17.08 & 37.21 \\
\hline & & Particles are not diffused fully and gel formation on upper surface (point B) & 37.56 & 18.73 & 14.82 & 28.89 \\
\hline
\end{tabular}

60FA40ZS) are characterized with restricted reaction on the particles upper surface and produced gels are more scattered, more non-bridging particles are therefore observed (Fig. 6a and 6b). Although, particles are started to refine after slag introduction (Fig. $6 \mathrm{~b}$ and $6 \mathrm{c}$ ) due to improve in reactivity and higher rate of dissolution in presence of $\mathrm{Ca}$. In the sample of 60FA40ZS, porous type of geopolymer gel (N-A-S-H) (point A of Fig. 6b) is formed as main reaction product in discrete way in most part of the matrix. This gel is derived by alkali activation of fly ash and little incorporation of calcium is detected through EDX. Similar findings are reported in published literatures (Nath and Sarker, 2014; Gao et al., 2015; Djobo et al., 2016; Nath, 2018). The particle shape irregularity increases with further slag addition (Fig. 6c). The amount of $\mathrm{Ca}$ increases and subsequently $\mathrm{Na} / \mathrm{Ca}$ ratio decreases with $80 \%$ slag inclusion due to formation of more C- $(N)$-A-S-H gel (Fig. 6c, point A). The partially reacted spherical particles are seen to be in less numbers and a matrix with bridged particles has been developed. ZS derived binder (Fig. 6d, point A) is distinguished with Ca enrich dense gels, C(A)-S-H with small amount of $\mathrm{Na}$ in structure. This leads to development of more uniform compact microstructure, combine with well reacted matrix and less un-reacted particles with well bridging with the produced gel. Presence of pores, a common feature is observed in the reacted matrix of all samples. The pore sizes are varied from micron to submicron size. Due to variation in chemistry of the starting materials, alternation in their respective gel composition is examined through EDX analysis (Table 3). However, produced gels are existed together without having any separate identity. The blended micrograms are detected with the presence of hybrid gels (C/N-A-S-H). Such gels are not only formed by intermixed of FA and ZS derived gels but also may result from either (a) replacement of Na by Ca into N-(A)-S-H (with Q4 framework silicate structure) or, (b) Na incorporation in chain silicate of C-(A)-S-H gels (Yip et al., 2005; Garcra-Lodeiro et al., 2011; Ismail et al., 2014). The count of un-reacted and non-bridging particles is reduced with inclusion of ZS in place of FA. The ZS, rich with $\mathrm{Ca}$, produces calcium bearing hydrated products, C-A-S-H along with geopolymer binder. This contributes to improve the binding capability, and enhances the physical properties and mechanical strength of the ZS rich geopolymers.

\subsection{Mechanical properties}

The compressive strength of hardened geopolymer paste samples is shown in Fig. 7. The compressive strength is improved with introduction of ZS which is further supported by ICC result and SEM observation. This result can be explained with the production of Ca rich dense gel and development of compact microstructure. The maximum strength, $\sim 71 \mathrm{MPa}$ is achieved with 100ZS sample after 28-days curing. This is associated with the higher reactive component of the slag, which dissolute and hydrate faster and produces Ca bearing gels additionally, along with hydrated geopolymeric (N-A-S-H) gel (Nath and Sarker, 2014; Gao et al., 2015; Djobo et al., 2016; Nath and Kumar, 2019a). A significant strength development at early stage ( 7 days) has been recorded when $\geq 80 \mathrm{wt} \% \mathrm{ZS}$ is added. The compressive strength of 100FA and FA rich blends (80FA and 60FA) is low due to slow activation of fly

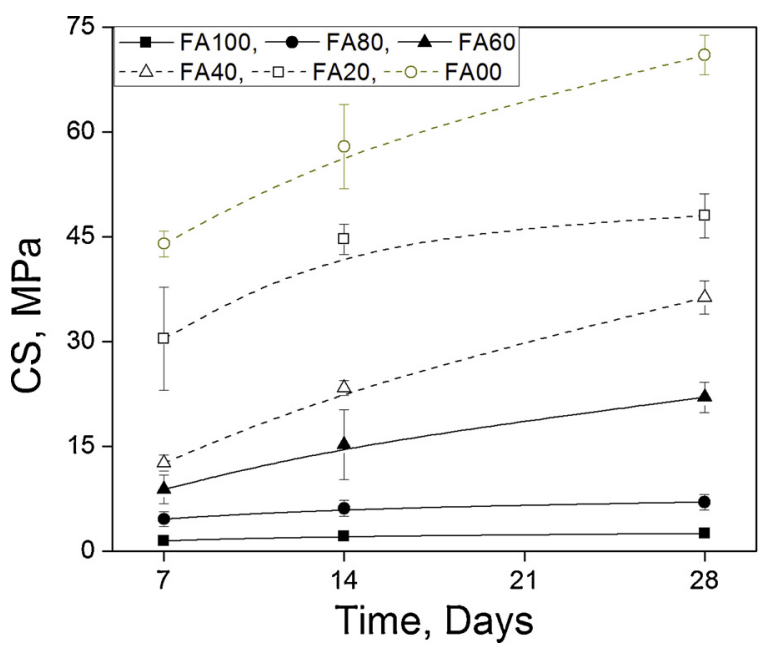

Fig. 7. Compressive strength of geopolymer cement paste samples.

ash at room temperature $\left(27 \pm 2{ }^{\circ} \mathrm{C}\right)$ with moderate alkali concentration $(6 \mathrm{M})$, coherent with other reported results (Fernández-Jiménez and Palomo, 2003; Nath et al., 2014; Nath and Kumar, 2017). The measured strengths are seen to be increase with all samples with aging. This result is ascribed with continual reaction and simultaneous binder formation from alkali activation of both FA and ZS. The initial and final strength is considerably high in ZS rich blends, because of faster dissolution and subsequent reaction of the ZS (ICC result), which leads to generation of more gel binder and development of compact microstructure (SEM). This can be related with more reactive constituents of the ZS which are more susceptible to alkali attack than FA, and produces an adequate amount of gel binder which enhances the binding capability and achieves higher mechanical strength.

\section{Production and testing of paver samples}

To explore the suitability of FA and ZS for paving block production, 60FA40ZS and 20FA80ZS batches have been tested for paver blocks production. The followed process steps are -

i FA and ZS are dry mixed in appropriate proportion for $3 \mathrm{~min}$ in a mechanical mixer. Then alkali solution, as used for compressive strength testing samples preparation is added and mixed for another $3 \mathrm{~min}$.

ii After mixing the homogeneous dough is casted into polyvinyl chloride (PVC) moulds and subjected to vibration for $1 \mathrm{~min}$ on a vibratory machine. Thereafter, the moulds are covered with plastic lid to reduce the moisture loss, and then hardened samples are demoulded after $24 \mathrm{~h}$ and left for curing at room temperature for 28 days.

The process flow sheet with paving block samples image is presented in Fig. 8. The properties of the produced paving blocks are tested 


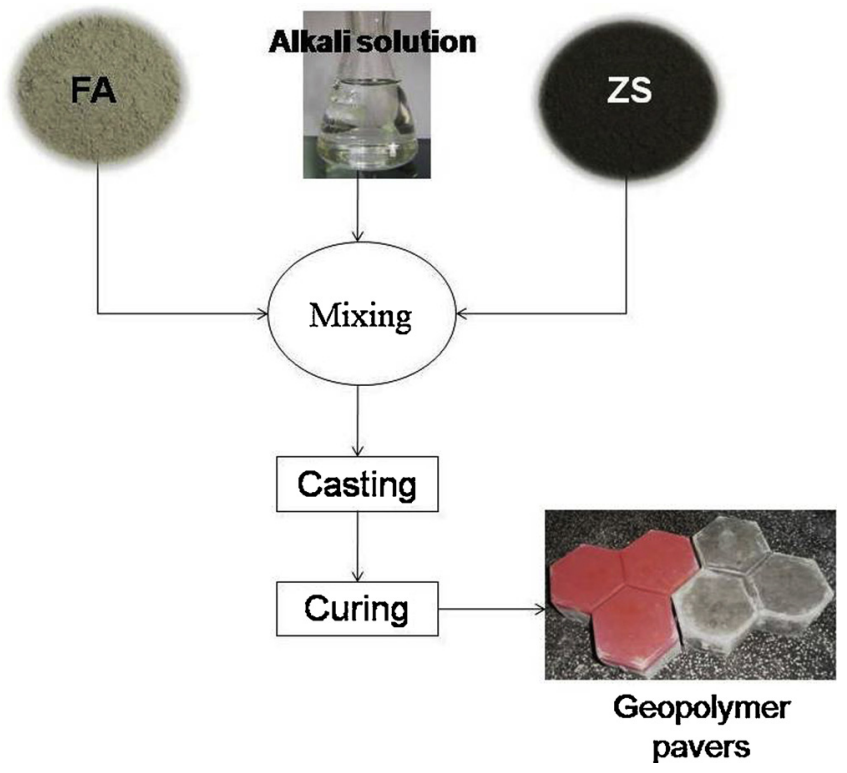

Fig. 8. Process flow sheet of geopolymer pavers block production.

as per Indian standard IS 15658 specification and the results are shown in Table 4. The properties of the paving blocks can be customized with the variation of process parameters such as alkali concentration, $\mathrm{NaOH}$ to silicate ratio, curing conditions etc. In the present work, moderate alkali concentration ( $6 \mathrm{M} \mathrm{NaOH}), 1: 1$ alkali to silicate ratio and ambient temperature for curing is selected. Higher alkali concentrations can results higher strength but it is very corrosive and difficult to handle and possibility of alkali leaching is higher and sometimes it hinders the reaction due to trafficking of $\mathrm{OH}^{-}$. Higher amount of silicate is not economically favourable also reduces the workability of the paste. Geopolymer is considered as potential alternative of cement. Cement is applied and cured at ambient condition. Therefore, ambient curing is followed to produce paver blocks. Rather heat curing of huge construction site is not a feasible process.

To check the environment suitability of the paver blocks, TCLP results are presented in Table 5. The leaching of heavy and toxic metals is within permissible limit. To understand the role of FA which has more potential to immobilize the heavy metals, leach liquors samples are shown in Fig. 9. Leach liquor of 100FA is purely transparent, because of minimum leaching. With increasing ZS, the color of leach liquor changes and becomes dark due to more leaching. Further, it has been seen that the color is more yellowish with higher slag content which indicates formation of new sulphate bearing compound under highly alkaline condition. Possibly this has been easily leached due to low $\mathrm{Si}$ / $\mathrm{Al}$ ratio in the ZS derived geopolymer network. However, both blended geopolymer matrix meets the US-EPA 1311 standard of heavy metal leaching limits, but FA plays an important role on immobilization by forming geopolymer with $\mathrm{Si} / \mathrm{Al} \sim 1.6$ and to mitigate the leaching of toxic metals, agrees with other reported researches (Alex et al., 2013; Kumar and Kumar, 2013; Xia et al., 2019). The leaching of heavy/toxic
Table 5

The leaching test results of paving blocks.

\begin{tabular}{lllll}
\hline Toxic elements & USEPA & 60FA60ZS & 20FA80ZS & Remarks \\
\hline $\mathrm{As}$ & 5.0 & 1.88 & 2.97 & Complies \\
$\mathrm{Cd}$ & 1.0 & 0.003 & 0.001 & Complies \\
$\mathrm{Pb}$ & 5.0 & 0.02 & 0.05 & Complies \\
$\mathrm{Cr}$ & 5.0 & 0.006 & 0.01 & Complies \\
$\mathrm{Se}$ & 1.0 & 0.002 & 0.001 & Complies \\
$\mathrm{Ba}$ & 100.0 & Not found & Not found & Complies \\
$\mathrm{Hg}$ & 5.0 & Not found & Not found & Complies \\
$\mathrm{Ag}$ & 5.0 & Not found & Not found & Complies \\
\hline
\end{tabular}

All elements are in ppm level.

metals from geopolymer matrix is strongly depended on nature of metal cation and characteristics of leaching solution for instance, $\mathrm{Cd}, \mathrm{Cr}$ and $\mathrm{Pb}$ is immobilized effectively by chemical retention with geopolymer network former (Zhang et al., 2007, 2008; Izquierdo et al., 2009). The $\mathrm{Pb}$ concentration in leach liquor is increasing with $\mathrm{ZS}$ inclusion due to alternation of geopolymer network. This is in consistent with Lee et al. (2016), where $\mathrm{Pb}$ is stabilized efficiently inside FA based geopolymer structure with $\mathrm{Si} / \mathrm{Al} \sim 2$. The leaching concentration of As is increasing with ZS, which can be explained with higher iron content of the blends, in line with Fernandez-Jimenez et al. (2005), where these authors examined that As immobilization is hindered by high Fe content. The degree of heavy metal leaching is associated to some extent with breakdown of geopolymer matrix. As a result, FA and ZS show different extent of leaching. The stabilization of heavy metal is firmly associated to the binder microstructure (Zhang et al., 2008) and chemical composition (van Jaarsveld and van Deventer, 1999). Zhang et al. (2008) also reported that certain heavy metal complex can contribute high strength development. Probably for this reason ZS derived geopolymer is achieved very high strength in the present study. Therefore, optimum activator dosages and synthesis conditions is required to confirm the environmental quality of the resultant product without any adverse effect on the mechanical strength and long-term durability.

\section{Conclusions}

In the present research the potential for practical application of FA and ZS as raw material for geopolymer synthesis has been examined. The following conclusions are drawn from this work:

1 An industrial byproduct (FA) and a hazardous waste (ZS) are solidified/stabilized through geopolymerization at ambient condition. The paving block samples are developed by using blends of FA and ZS.

2 Compare to FA, ZS is more reactive at ambient condition with moderate alkali concentration, because it contains more reactive oxide components. The peak intensity is amplified and shifted towards lower time with the introduction of ZS. The shortening of dormant phase of reaction in slag dominated batches signifies faster reaction.

3 The structural alteration of the raw materials after geopolymerization is affirmed by XRD analysis, change of amorphous hump

Table 4

Properties of paving blocks and its compliance with Indian Standard (IS).

\begin{tabular}{|c|c|c|c|c|}
\hline Sl. no & Properties & IS 15658: 2006 & 60FA40ZS & 20FA80ZS \\
\hline 1. & Visual Inspection & $95 \%$ free from visual defect & $95 \%$ free from visual defect & $95 \%$ free from visual defect \\
\hline 2. & Size and tolerance (mm) & \pm 2 & \pm 1.5 & \pm 1 \\
\hline 3. & Water absorption (\%) & 7 & 7 & 6 \\
\hline 4. & Compressive strength $\left(\mathrm{N} / \mathrm{mm}^{2}\right)$ & 30 & $>30$ & $>40$ \\
\hline 5. & Flexural strength $\left(\mathrm{N} / \mathrm{mm}^{2}\right)$ & 3 & $>3.5$ & $>5$ \\
\hline 6. & Abrasion resistance (mm) & 2 & $<1.2$ & $<1$ \\
\hline
\end{tabular}

Serial numbers 1-4 are obligatory requirement and 5 and 6 are optional requirement. 


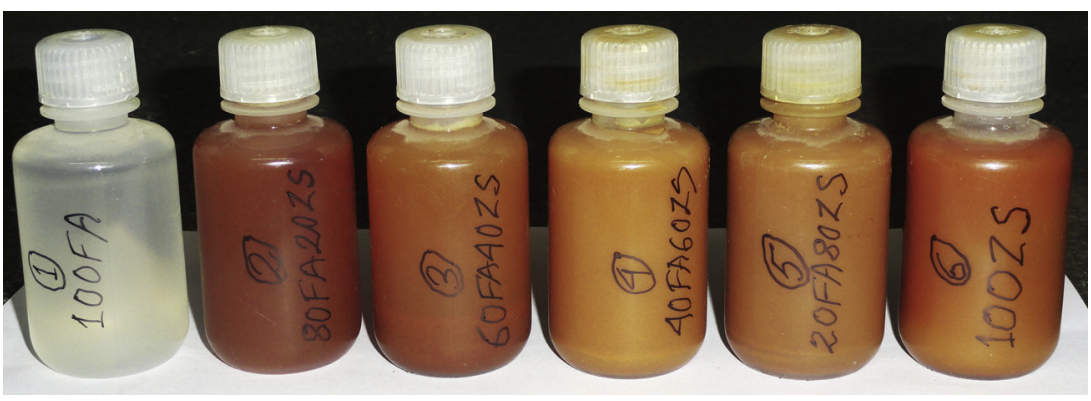

Fig. 9. Change of leach liquor color with ZS percentage.

characteristics and crystalline peak intensity reduction.

4 Hybrid N/C-A-S-H gels are recognized via SEM-EDX analysis as the prime reaction product in the reacted matrix of blended samples. Basically, N-A-S-H is produced by alkali activation of FA which intakes small amount of Ca into structure. In slag rich blends, C-(N)-A$\mathrm{S}$-H gel is readily formed by activation of ZS with alkali and includes $\mathrm{Na}$ from activator solution.

5 The compressive strength is improved with FA replacement. The higher reactivity (ICC result) of ZS and generation of more hydrated phases rich with calcium, is crucial for high strength development. The un-reacted and non-bridged particles are bonded well with the produced gel in the reacted matrix and build stronger matrices.

6 Paving blocks using 40-80 \% ZS has been produced and meets IS:15658 specification. These samples are environment friendly in terms of leaching of toxic and heavy metals and comply with USEPA 1311 standard. Further, research on long term durability and performance results need to be generate for commercial adoption of these blocks.

7 According to the obtained results from the present study, synergistic utilization of FA and ZS for synthesis of geopolymer product in the form of paver blocks at ambient conditions can be a feasible process. FA and ZS works as supplement to each and other. ZS is rich with reactive $\mathrm{Ca}$ which helps to overcome the slow reaction of FA with alkali at ambient temperature, and enhance the fly ash utilization into geopolymeric materials. On the other side, chemical composition of $\mathrm{ZS}$ with $\mathrm{Si} / \mathrm{Al}$ ratio $\sim 3.1$ and high iron content can hinder the effective immobilization of heavy and toxic metals. Thus, mixing with FA can improve the immobilization potential and reduce the leaching of metals of the blends.

\section{Acknowledgements}

The author is grateful to the Director, CSIR-National Metallurgical Laboratory, Jamshedpur, India for his kind permission to publish this paper. Tata Power Ltd., Jamshedpur, India and Hindustan Zinc Ltd., Rajasthan, India is acknowledged for sending fly ash and zinc slag respectively. The technical support from CSIR-NML staff is highly appreciated.

\section{References}

Alex, T.C., Kalinkin, A.M., Nath, S.K., Gurevich, B.I., Kalinkina, E.V., Tyukavkina, V.V., Kumar, S., 2013. Utilization of zinc slag through geopolymerization: influence of milling atmosphere. Int. J. Miner. Process. 123, 102-107.

Chindaprasirt, P., Chareerat, T., Sirivivatnanon, V., 2007. Workability and strength of coarse high calcium fly ash geopolymer. Cem. Concr. Compos. 29, 224-229.

Criado, M., Palomo, A., Fernandez-Jimenez, A., 2005. Alkali activation of fly ashes. Part 1: effect of curing conditions on the carbonation of the reaction products. Fuel 84, 2048-2054.

Davidovits, J., 1989. Geopolymers and geopolymeric materials. J. Therm. Anal. 35, 429-441.

Djobo, J.N.Y., Tchakoute, H.K., Ranjbar, N., Elimbi, A., Tchadjie, L.N., Njopwouo, D., 2016. Gel composition and strength properties of alkali-activated oyster shell-volcanic ash: effect of synthesis conditions. J. Am. Ceram. Soc. 99, 3159-3166.

EPA 1311, 1992. Toxicity Characteristic Leaching Procedure. US Environmental
Protection Agency, US.

Fernandez-Jimenez, A., Palomo, A., 2003. Characterisation of fly ashes. Potential reactivity as alkaline cements. Fuel 82, 2259-2265.

Fernandez-Jimenez, A., Palomo, A., Macphee, D.E., Lachowski, E.E., 2005. Fixing arsenic in alkali-activated cementitious matrices. J. Am. Ceram. Soc. 88, 1122-1126.

Fernández-Jiménez, A., Palomo, A., López-Hombrados, C., 2006. Engineering propertiesof alkali activated fly ash concrete. ACI Mater. J. 103, 106-112.

Fernández-Pereira, C., Luna-Galiano, Y., Pérez-Clemente, M., Leiva, C., Arroyo, F., Villegas, R., Vilches, L.F., 2018. Immobilization of heavy metals (Cd, Ni or Pb) using aluminate geopolymers. Mater. Lett. 227, 184-186.

Gao, X., Yu, Q.L., Brouwers, H.J.H., 2015. Reaction kinetics, gel character and strength of ambient temperature cured alkali activated slag-fly ash blends. Constr. Build. Mater. 80, 105-115.

Garcia-Lodeiro, I., Palomo, A., Fernandez-Jimenez, A., Macphee, D.E., 2011. Compatibility studies between N-A-S-H and C-A-S-H gels. Study in the ternary diagram $\mathrm{Na}_{2} \mathrm{O}-\mathrm{CaO}-\mathrm{Al}_{2} \mathrm{O}_{3}-\mathrm{SiO}_{2}-\mathrm{H}_{2} \mathrm{O}$. Cem. Concr. Res. 41, 923-931.

Garg, N., White, C.E., 2017. Mechanism of zinc oxide retardation in alkali-activated materials: an: in situ X-ray pair distribution function investigation. J. Mater. Chem. A. 5 (23), 11794-11804.

Gartner, E., Hirao, H., 2015. A review of alternative approaches to the reduction of $\mathrm{CO}_{2}$ emissions associated with the manufacture of the binder phase in concrete. Cem. Concr. Res. 78, 126-142.

Hassan, A., Arif, M., Shariq, M., 2019. Use of geopolymer concrete for a cleaner and sustainable environment-A review of mechanical properties and microstructure. J. Clean. Prod. 223, 704-728.

Hu, H., Deng, Q., Li, C., Xie, Y., Dong, Z., Zhang, W., 2014. The recovery of Zn and Pb and the manufacture of lightweight bricks from zinc smelting slag and clay. J. Hazard. Mater. 271, 220-227.

IS 15658, 2006. Precast Concrete Blocks for Paving. Bureau of Indian Standards, India.

Ismail, I., Bernal, S.A., Provis, J.L., Nicolas, R.S., Hamdan, S., van Deventer, J.S.J., 2014. Modification of phase evolution in alkali-activated blast furnace slag by the incorporation of fly ash. Cem. Concr. Compos. 45, 125-135.

Izquierdo, M., Querol, X., Davidovits, J., Antenucci, D., Nugteren, H., Fernández-Pereira, C., 2009. Coal fly ash-slag-based geopolymers: microstructure and metal leaching. J. Hazard. Mater. 166, 561-566.

Kiventera, J., Lancellotti, I., Catauro, M., Poggetto, F.D., Leonelli, C., Illikainen, M., 2018. Alkali activation as new option for gold mine tailings inertization. J. Clean. Prod. 187, 76-84.

Koplík, J., Solny, T., Kalina, L., Másilko, J., 2018. Immobilization of Sr2+, Bi3 + and $\mathrm{Zn} 2+$ in alkali-activated materials based on blast furnace slag and fly ash. Key Eng. Mater. 761, 15-18.

Kumar, A., Kumar, S., 2013. Development of paving blocks from synergistic use of red mud and fly ash using geopolymerization. Constr. Build. Mater. 38, 865-871.

Kumar, S., Mucsi, G., Kristaly, F., Pekker, P., 2017. Mechanical activation of fly ash and its influence on micro and nano-structural behaviour of resulting geopolymer. Adv Powder Technol. 28, 805-813.

Lee, N.K., Lee, H.K., 2013. Setting and mechanical properties of alkali-activated fly ash/ slag concrete manufactured at room temperature. Constr. Build. Mater. 47, 1201-1209.

Lee, S., van Riessen, A., Chon, C.M., Kang, N.H., Jou, H.T., Kim, Y.J., 2016. Impact of activator type on the immobilisation of lead in fly ash-based geopolymer. J. Hazard. Mater. 305, 59-66.

Lirer, S., Liguori, B., Capasso, I., Flora, A., Caputo, D., 2017. Mechanical and chemical properties of composite materials made of dredged sediments in a fly-ash based geopolymer. J. Environ. Manage. 191, 1-7.

Luhar, S., Chaudhary, S., Luhar, I., 2019. Development of rubberized geopolymer concrete: strength and durability studies. Constr. Build. Mater. 204, 740-753.

Ma, Y., Hu, J., Ye, G., 2012. The effect of activating solution on the mechanical strength, reaction rate, mineralogy, and microstructure of alkali-activated fly ash. J. Mater. Sci. 47, 4568-4578.

Millán-Corrales, G., Magallanes-Rivera, R.X., González-López, J.R., Zaldivar-Cadena, A.A., Figueroa-Torres, M.Z., 2018. Synthesis of an alternative hydraulic binder by alkali activation of a slag from lead and Zinc processing. Waste Biomass Valor. https://doi.org/10.1007/s12649-018-0363-1.

Nath, S.K., Kumar, S., 2013. Influence of iron making slags on strength and microstructure of fly ash geopolymer. Constr. Build. Mater. 38, 924-930.

Nath, P., Sarker, P.K., 2014. Effect of GGBFS on setting, workability and early strength properties of fly ash geopolymer concrete cured in ambient condition. Constr. Build. 
Mater. 66, 163-171. https://doi.org/10.1016/j.conbuildmat.2014.05.080.

Nath, S.K., Mukherjee, S., Maitra, S., Kumar, S., 2014. Ambient and elevated temperature geopolymerization behavior of class F fly ash. Trans. Ind. Ceram. Soc. 73, 126-132.

Nath, S.K., Kumar, S., 2016. Evaluation of the suitability of ground granulated silicomanganese slag in Portland slag cement. Constr. Build. Mater. 125, 127-134.

Nath, S.K., Maitra, S., Mukherjee, S., Kumar, S., 2016. Microstructural and morphological evolution of fly ash based geopolymers. Constr. Build. Mater. 111, 758-765.

Nath, S.K., Kumar, S., 2017. Reaction kinetics, microstructure and strength behavior of alkali activated silico-manganese (SiMn) slag - fly ash blends. Constr. Build. Mater. $147,371-379$.

Nath, S.K., 2018. Geopolymerization behavior of ferrochrome slag and fly ash blends. Constr. Build. Mater. 181, 487-494.

Nath, S.K., Kumar, S., 2019a. Influence of granulated silico-manganese slag on compressive strength and microstructure of ambient cured alkali-activated fly ash binder. Waste Biomass Valor. https://doi.org/10.1007/s12649-018-0213-1.

Nath, S.K., Kumar, S., 2019b. Reaction kinetics of fly ash geopolymerization: role of particle size controlled by using ball mill. Adv. Powder Technol. 30, 1079-1088.

Nazari, A., Sanjayan, J.G., 2015. Synthesis of geopolymer from industrial wastes. J. Clean. Prod. 99, 297-304.

Nie, Q., Hu, W., Huang, B., Shu, X., He, Q., 2019. Synergistic utilization of red mud for flue-gas desulfurization and fly ash- based geopolymer preparation. J. Hazard. Mater. $369,503-511$.

Ogundiran, M.B., Nugteren, H.W., Witkamp, G.J., 2013. Immobilisation of lead smelting slag within spent aluminate-fly ash based geopolymers. J. Hazard. Mater. 248-249, 29-36.

Onisei, S., Pontikes, Y., Gerven, T.V., Angelopoulos, G.N., Velea, T., Predica, V., Moldovan, P., 2012. Synthesis of inorganic polymers using fly ash and primary lead slag. J. Hazard. Mater. 205-206, 101-110.

Park, S.M., Jang, J.G., Lee, N.K., Lee, H.K., 2016. Physicochemical properties of binder gel in alkali-activated fly ash/slag exposed to high temperatures. Cem. Concr. Res. 89, $72-79$.
Rodríguez, E.D., Bernal, S.A., Provis, J.L., Paya, J., Monzo, J.M., Borrachero, M.V., 2013. Effect of nanosilica-based activators on the performance of an alkali-activated fly ash binder. Cem. Concr. Compos. 35, 1-11.

Temuujin, J., Williams, R.P., van Riessen, A., 2009. Effect of mechanical activation of fly ash on the properties of geopolymer cured at ambient temperature. J. Mater. Process. Technol. 209, 5276-5280.

van Jaarsveld, J.G.S., van Deventer, J.S.J., 1999. The effect of metal contaminants on the formation and properties of waste-based geopolymers. Cem. Concr. Res. 29, 1189-1200.

Wijnen, P.W.J.G., Beelen, T.P.M., de Haan, J.W., Rummens, C.P.J., van de Ven, L.J.M., van Santen, R.A., 1989. Silica gel dissolution in aqueous alkali metal hydroxides studied by 29Si NMR. J. Non-Cryst. Solids 109, 85-94.

Xia, M., Muhammad, F., Zeng, L., Li, S., Huang, X., Jiao, B., Shiau, Y.C., Li, D., 2019. Solidification/stabilization of lead-zinc smelting slag in composite based geopolymer. J. Clean. Prod. 209, 1206-1215.

Xu, H., Gong, W., Syltebo, L., Izzo, K., Lutze, W., Pegg, I.L., 2014. Effect of blast furnace slag grades on fly ash based geopolymer waste forms. Fuel 133, 332-340.

Yang, K.H., Song, J.K., Song, K.I., 2013. Assessment of $\mathrm{CO}_{2}$ reduction of alkali-activated concrete. J. Clean. Prod. 39, 265-272.

Yip, C.K., Lukey, G.C., van Deventer, J.S.J., 2005. The coexistence of geopolymeric gel and calcium silicate hydrate at the early stage of alkaline activation. Cem. Concr. Res. 35, 1688-1697.

Yun-Ming, L., Cheng-Yong, H., Bakri, M.M.A., Hussin, K., 2016. Structure and properties of clay-based geopolymer cements: a review. Prog. Mater. Sci. 83, 595-629.

Zhang, Y., Sun, W., Chen, Q., Chen, L., 2007. Synthesis and heavy metal immobilizationbehaviors of slag based geopolymers. J. Hazard. Mater. 143, 206-213.

Zhang, J., Provis, J.L., Feng, D., van Deventer, J.S.J., 2008. Geopolymers for immobilization of $\mathrm{Cr} 6+, \mathrm{Cd} 2+$, and Pb2 +. J. Hazard. Mater. 157, 587-598.

Zhang, Z., Li, L., Ma, X., Wang, H., 2016. Compositional, microstructural and mechanical properties of ambient condition cured alkali-activated cement. Constr. Build. Mater. $113,237-245$. 